Article

\title{
Construction of efficient active sites through cyano-modified graphitic carbon nitride for photocatalytic $\mathrm{CO}_{2}$ reduction
}

\author{
Fang Li a,b, Xiaoyang Yue a, Haiping Zhou c, Jiajie Fan d, Quanjun Xiang a,b,* \\ a State Key Laboratory of Electronic Thin Film and Integrated Devices, University of Electronic Science and Technology of China, Chengdu 610054, \\ Sichuang, China \\ b Yangtze Delta Region Institute (Huzhou), University of Electronic Science and Technology of China, Huzhou 313001, Zhejiang, China \\ c School of Materials and Energy, University of Electronic Science and Technology of China, Chengdu 610054, Sichuang, China \\ d School of Materials Science and Engineering, Zhengzhou University, Zhengzhou, 450002, Henan, China
}

\section{A R T I C L E I N F}

\section{Article history:}

Received 12 January 2021

Accepted 1 February 2021

Available online 5 May 2021

\section{Keywords:}

Graphitic carbon nitride

Cyano group modification

Active sites

Electron acceptor

Porous structure

Photocatalytic $\mathrm{CO}_{2}$ reduction

\begin{abstract}
A B S T R A C T
The active site amount of photocatalysts, being the key factors in photocatalytic reactions, directly affects the photocatalytic performance of the photocatalyst. Pristine graphitic carbon nitride ( $\mathrm{g}-\mathrm{C}_{3} \mathrm{~N}_{4}$ ) exhibits moderate photocatalytic activity due to insufficient active sites. In this study, cyano-modified porous $\mathrm{g}-\mathrm{C}_{3} \mathrm{~N}_{4}$ nanosheets (MCN-0.5) were synthesized through molecular self-assembly and alkali-assisted strategies. The cyano group acted as the active site of the photocatalytic reaction, because the good electron-withdrawing property of the cyano group promoted carrier separation. Benefiting from the effect of the active sites, MCN-0.5 exhibited significantly enhanced photocatalytic activity for $\mathrm{CO}_{2}$ reduction under visible light irradiation. Notably, the photocatalytic activity of MCN-0.5 was significantly reduced when the cyano groups were removed by hydrochloric acid $(\mathrm{HCl})$ treatment, further verifying the role of cyano groups as active sites. The photoreduction of $\mathrm{Pt}$ nanoparticles provided an intuitive indication that the introduction of cyano groups provided more active sites for the photocatalytic reaction. Furthermore, the controlled experiments showed that $\mathrm{g}-\mathrm{C}_{3} \mathrm{~N}_{4}$ grafted with cyano groups using melamine as the precursor exhibited enhanced photocatalytic activity, which proved the versatility of the strategy for enhancing the activity of $\mathrm{g}-\mathrm{C}_{3} \mathrm{~N}_{4}$ via cyano group modification. In situ diffuse reflectance infrared Fourier transform spectroscopy and theoretical calculations were used to investigate the mechanism of enhanced photocatalytic activity for $\mathrm{CO}_{2}$ reduction by cyano-modified g- $\mathrm{C}_{3} \mathrm{~N}_{4}$. This work provides a promising route for promoting efficient solar energy conversion by designing active sites in photocatalysts.
\end{abstract}

(C) 2021, Dalian Institute of Chemical Physics, Chinese Academy of Sciences. Published by Elsevier B.V. All rights reserved.

\section{Introduction}

For overcoming the challenges of global warming and energy shortage, the photocatalytic reduction of $\mathrm{CO}_{2}$ to $\mathrm{CO}$ and $\mathrm{CH}_{4}$ is considered to be a feasible solution [1-6]. As a promising semiconductor photocatalyst, graphitic carbon nitride $\left(\mathrm{g}-\mathrm{C}_{3} \mathrm{~N}_{4}\right)$ has attracted widespread attention owing to its medium bandgap and good stability [7-12]. However, the pristine g- $\mathrm{C}_{3} \mathrm{~N}_{4}$ prepared using the traditional calcination method has several drawbacks, such as serious carrier recombination, in-

\footnotetext{
*Corresponding author. Tel/Fax: +86-28-83207063; E-mail: xiangqj@uestc.edu.cn

This work was supported by the National Natural Science Foundation of China (51672099, 52073263), Sichuan Science and Technology Program (2019JDRC0027, 2019YFG0222), and the Fundamental Research Funds for the Central Universities (2017-QR-25).

DOI: 10.1016/S1872-2067(20)63776-7 | http://www.sciencedirect.com/journal/chinese-journal-of-catalysis | Chin. J. Catal., Vol. 42, No. 9, September 2021
} 
sufficient active sites, and poor light absorption capacity, limiting the photocatalytic performance of $g-\mathrm{C}_{3} \mathrm{~N}_{4}$ [13-15]. In particular, photocatalytic reactions usually occur at active sites, and the number of active sites directly affects the photocatalytic activity of g- $\mathrm{C}_{3} \mathrm{~N}_{4}$.

In order to increase the number of active sites of $\mathrm{g}-\mathrm{C}_{3} \mathrm{~N}_{4}$, various strategies have been implemented, including heteroatom doping [16,17], surface modification [18], and vacancy engineering [19]. Among them, surface modification is the most effective strategy to increase the number of active sites [20,21]. Theoretically, the photocatalytic activity of a photocatalyst depends on the electronic structure of the material, and surface modification will change the local electronic structure and provide more active sites for the photocatalytic reaction. The cyano group possesses a strong ability to extract electrons and is considered to be an active site for photocatalytic reactions [22]. Lau et al. [23] reported that cyanamide defects promoted carrier delocalization and acted as active sites to enhance hydrogen production activity. Zhang et al. [24] reported that cyano-modified $\mathrm{g}-\mathrm{C}_{3} \mathrm{~N}_{4}$ promoted the activation of oxygen molecules and further improved the activity for oxidative coupling of amines. However, the study of the cyano group as the active site in $\mathrm{CO}_{2}$ photoreduction has only received sporadic attention, and the in-depth mechanism for the enhanced activity of g- $\mathrm{C}_{3} \mathrm{~N}_{4}$ modified by cyano groups is still unclear.

Constructing a porous structure is an effective measure to expose active sites. The porous structure can effectively improve the stacking of nanosheets, and the interconnected porous network forms a unique transmission channel to further promote the migration of carriers $[25,26]$. The porous structure can increase the chance of contact between the reactant and the active site, providing a good platform for the exposure of the active site.

In this study, cyano-modified porous $\mathrm{g}-\mathrm{C}_{3} \mathrm{~N}_{4}$ nanosheets (MCN-0.5) were synthesized through molecular self-assembly and alkali-assisted strategies. The cyano group acted as the active site for the photocatalytic reaction. Benefiting from the effect of the active sites, MCN-0.5 exhibited significantly enhanced activity for $\mathrm{CO}_{2}$ reduction. The production rates of $\mathrm{CO}$ and $\mathrm{CH}_{4}$ over $\mathrm{MCN}-0.5$ reached 13.7 and $0.6 \mu \mathrm{mol} \cdot \mathrm{h}^{-1} \cdot \mathrm{g}^{-1}$, which were 2.5 and 2 times, respectively, that of $g-\mathrm{C}_{3} \mathrm{~N}_{4}$ prepared by the traditional calcination method (TCN). Notably, the removal of the cyano group led to a decrease in the photocatalytic activity of MCN-0.5, confirming the role of the active site. The pho- toreduction of Pt nanoparticles indicated that MCN-0.5 possessed more active sites. Furthermore, controlled experiments using a cyano group grafted with melamine as the precursor proved the versatility of the strategy for enhancing the activity of g- $\mathrm{C}_{3} \mathrm{~N}_{4}$ via cyano group modification. The mechanism of enhanced photocatalytic activity for $\mathrm{CO}_{2}$ reduction by cyano-modified g- $\mathrm{C}_{3} \mathrm{~N}_{4}$ was investigated using in situ diffuse reflectance infrared Fourier transform spectroscopy and theoretical calculations.

\section{Experimental}

\subsection{Materials}

The chemical reagents used in the experiment were of analytical grade. $\mathrm{KOH}(90 \%)$ and ethanol $(99.7 \%)$ were provided by Chengdu Kelon Chemical Reagent Factory. Cyanuric acid (98\%) and melamine (99\%) were produced by Shanghai Aladdin Biochemical Technology Co., Ltd.

\subsection{Sample preparation}

\subsubsection{Preparation of $M C N-0.5$ and $M C N$}

$5 \mathrm{~g}$ melamine and $5.1 \mathrm{~g}$ of cyanuric acid were separately dispersed in $200 \mathrm{~mL}$ of ethanol solution and stirred overnight [27]. The suspension was mixed and stirred for $30 \mathrm{~min}$, after which the mixture was centrifuged and dried. The sample prepared via molecular self-assembly was the precursor of $\mathrm{g}-\mathrm{C}_{3} \mathrm{~N}_{4}$ (CM). $8 \mathrm{~g}$ of dried CM and $0.5 \mathrm{~g}$ of $\mathrm{KOH}$ were dispersed in $20 \mathrm{~mL}$ of ethanol and immersed at $50^{\circ} \mathrm{C}$. The evaporated sample was ground and calcined at $550{ }^{\circ} \mathrm{C}$ for $4 \mathrm{~h}$ at a heating rate of 2.5 ${ }^{\circ} \mathrm{C} / \mathrm{min}$, and the obtained sample was MCN-0.5. The preparation process of MCN was similar to that of MCN-0.5, except that no KOH was added.

\subsubsection{Preparation of TCN-0.5 and TCN}

$8 \mathrm{~g}$ of melamine and $0.5 \mathrm{~g}$ of $\mathrm{KOH}$ were dispersed in $20 \mathrm{~mL}$ ethanol, and the mixture was impregnated to dryness at $50{ }^{\circ} \mathrm{C}$. Then, the dried sample was ground and calcined at $550{ }^{\circ} \mathrm{C}$ for 4 h. The obtained sample was denoted as TCN-0.5. TCN was prepared using the traditional calcination method. Melamine (5 g) was calcined at $550{ }^{\circ} \mathrm{C}$ for $4 \mathrm{~h}$ at a heating rate of $5^{\circ} \mathrm{C} / \mathrm{min}$.

\subsubsection{Preparation of $\mathrm{MCN}-0.5-\mathrm{HCl}$}

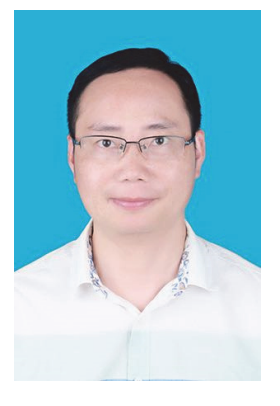

Quanjun Xiang received his Ph.D. degree in materials chemistry and physics in 2012 from Wuhan University of Technology. He was a postdoctoral fellow at the City University of Hong Kong from 2013 to 2015, and an associate professor from 2012 to 2017 at Huazhong Agricultural University. He is now a professor at the School of Electronic Science and Engineering, University of Electronic Science and Technology of China. His research interests include semiconductor photocatalysis, photocatalytic hydrogen production, $\mathrm{CO}_{2}$ reduction to hydrocarbon fuels. He has coauthored about 80 peer-reviewed papers, and these articles have been cited more than 12320 times by SCI. He has won the award of "Highly Cited Researchers" by Thomson Reuters and/or Clarivate Analytics for the third consecutive year in 2016-2020. In addition, he obtains 2 first prize in natural science of Hubei Province in 2016 and 2018, and the 17th young teacher award by Fok Ying Tong education foundation. He joined the editorial board of Chinese Journal of Catalysis in 2020. 
$300 \mathrm{mg}$ of the prepared MCN-0.5 sample was added to 25 $\mathrm{mL}$ of $\mathrm{HCl}(1 \mathrm{M})$ solution while stirring for $4 \mathrm{~h}$ [28]. The suspension was centrifuged and washed with deionized water. The resulting powder after drying at $50{ }^{\circ} \mathrm{C}$ was labeled as MCN-0.5-HCl.

\subsubsection{Preparation of MCN-0.5-Pt and MCN-Pt}

$30 \mathrm{mg}$ of MCN-0.5 and $30 \mathrm{mg}$ of MCN were dispersed separately in a $42 \mathrm{~mL}$ dilute solution of $\mathrm{H}_{2} \mathrm{PtCl}_{6} \cdot \mathrm{H}_{2} \mathrm{O}(0.1 \mathrm{mg} / \mathrm{mL})$. After 40 min of light irradiation, the mixture was filtered off with suction and washed with deionized water. The resulting samples after drying at $50{ }^{\circ} \mathrm{C}$ were marked as MCN-0.5-Pt and MCN-Pt.

\subsection{Characterization}

X-ray diffraction (XRD) patterns were obtained using an X-ray diffractometer (Bruker D8 ADVANCE) with $\mathrm{Cu} K_{\alpha}$ as the irradiation source at a scan rate of $15^{\circ} \mathrm{min}^{-1}$. Fourier-transform infrared (FTIR) spectra were recorded using a Thermo Fisher Nicolet Is10 spectrometer. Scanning electron microscopy (SEM) images were collected using FEI Inspect F50 (FSEM). Solid-state ${ }^{13} \mathrm{C}$ NMR spectra were acquired using a Bruker Advance III (400 MHz) spectrometer. Time-resolved photoluminescence (TRPL) spectra were recorded using FLSP920 (Edinburgh Instruments). Electron paramagnetic resonance (EPR) tests were conducted using a Bruker A300 spectrometer at room temperature. In situ diffuse reflectance infrared Fourier transform (DRIFT) data were obtained using a Nicolet iS50 FTIR spectrometer (Thermo Fisher, USA). UV-vis diffuse reflectance spectra (DRS) were obtained using PE Lambda $650 \mathrm{~s}$ (UV-vis spectrophotometer). Transmission electron microscopy (TEM) images, scanning TEM (STEM) images, and energy dispersive spectrometry (EDS) results were obtained using FEI Tecnai G2 F20 at an accelerating voltage of $200 \mathrm{kV}$. X-ray photoelectron spectroscopy (XPS) measurements were performed using Axis Supra. Density functional theory (DFT) calculations were performed using the projector-augmented plane-wave (PAW) method implemented in the Vienna ab initio simulation package (VASP). The exchange-correlation interactions were described by the Perdew-Burke-Eznerhof (PBE) generalized gradient approximation (GGA). An energy cutoff of $450 \mathrm{eV}$ was used in the calculation with a $k$-point mesh of dimensions $3 \times 3 \times 4$.

\subsection{Photoelectrochemical measurement}

The photoelectrochemical properties of the photocatalyst were evaluated using a three-electrode system CHI660E (Shanghai Chen Hua). Ag/AgCl (reference electrode) and $\mathrm{Pt}$ wire (counter electrode) were immersed in $0.1 \mathrm{M} \mathrm{Na}_{2} \mathrm{SO}_{4}$ solution. A $30 \mathrm{mg}$ photocatalyst, $0.5 \mathrm{~mL}$ ethanol, and $30 \mathrm{mg}$ polyethylene glycol were mixed and ground into a slurry, and then, the slurry was coated on FTO conductive glass (effective area 1 $\mathrm{cm}^{2}$ ). The working electrode was prepared after drying at 100 ${ }^{\circ} \mathrm{C}$ for $2 \mathrm{~h}$ [29]. A xenon lamp was employed as the light source for the transient photocurrent measurement, and the electro- chemical impedance spectroscopy (EIS) test was conducted in the $0.1-100000 \mathrm{~Hz}$ frequency range.

\subsection{Photocatalytic $\mathrm{CO}_{2}$ reduction measurement}

The photocatalytic $\mathrm{CO}_{2}$ reduction experiment was performed using Labsolar-6A (Perfectlight). $\mathrm{N}_{2}$ and $\mathrm{CO}_{2}$ were used as the carrier gas and reaction gas, respectively. $30 \mathrm{mg}$ of the photocatalyst and $0.5 \mathrm{~mL}$ of deionized water were placed in a shallow dish. Before introducing the reaction gas, the reactor system was evacuated. During the reaction, the Xenon lamp was used as the light source, and the water circulation system ensured that the system temperature was maintained at room temperature. Gas chromatography was used to detect the $\mathrm{CO}_{2}$ reduction products.

\section{Results and discussion}

The synthesis mechanism of MCN-0.5 is shown in Fig. 1(a). MCN-0.5 was synthesized via molecular self-assembly and a $\mathrm{KOH}$-assisted strategy. The formation of cyano groups was a process of deprotonation of $-\mathrm{C}-\mathrm{NH}_{2}$. The $\mathrm{OH}^{-}$released by the melting $\mathrm{KOH}$ may react with the amino groups at the edge of the $\mathrm{g}_{3} \mathrm{C}_{4}$, thus introducing cyano groups. During the calcina-

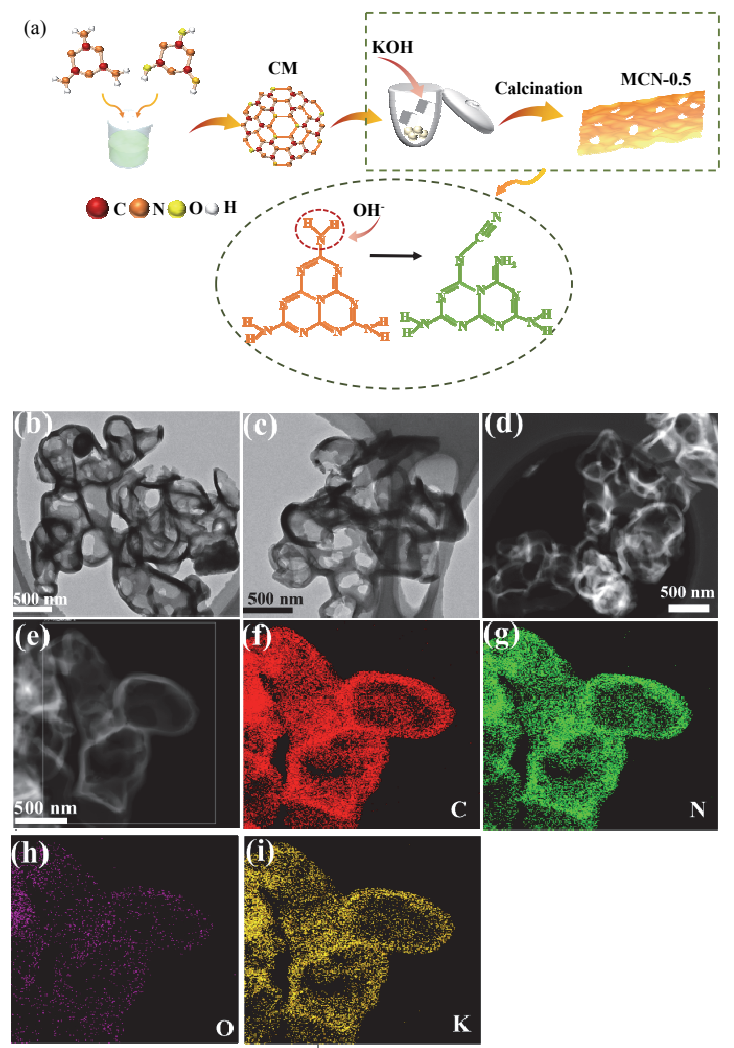

Fig. 1. (a) Schematic of MCN-0.5 synthesis; (b,c) TEM images of MCN-0.5; (d) STEM images of MCN-0.5; STEM image (e) and elemental mapping images ( $\mathrm{f}-\mathrm{i}$ ) of MCN-0.5 corresponding to $\mathrm{C}, \mathrm{N}, \mathrm{O}$, and K. During the thermal polymerization process, the $\mathrm{OH}^{-}$released when $\mathrm{KOH}$ melted reacted with the amino groups at the edge of $\mathrm{g}-\mathrm{C}_{3} \mathrm{~N}_{4}$ to introduce cyano groups, and ethanol molecules acted as intercalation molecules and were released in the form of gas, leaving pores in the nanosheets. 
tion process, ethanol molecules acted as intercalation molecules and were released in the form of gas, forming a porous sheet-like structure. Figs. 1(b)-(d) show the TEM and STEM images of MCN-0.5. The morphology of MCN-0.5 comprises nanosheets with a porous structure. Figs. 1(e) and 1(f)-(i) show the STEM image of MCN-0.5 and the corresponding EDS mapping images. $\mathrm{C}, \mathrm{N}$, and $\mathrm{O}$ elements were uniformly distributed on MCN-0.5. The small amount of K elements detected is attributed to residual impurities during the calcination process. Fig. 2 shows the SEM images of MCN-0.5 and MCN. The morphology of MCN-0.5 comprises porous nanosheets (Figs. 2(a) and (b)), which is similar to that of MCN (Figs. 2(c) and (d)), indicating that the introduction of cyano groups does not affect the morphology of the photocatalyst.

In order to explore the possible positions of cyano groups, the characterization of solid-state ${ }^{13} \mathrm{C}$ NMR was carried out (Fig. 3(a)). The peaks of MCN-0.5 and TCN-0.5 at $154\left(\mathrm{CN}_{3}\right)$ and 162 ppm $\left(\mathrm{CN}_{2}\left(\mathrm{NH}_{2}\right)\right)$ were detected [30]. For MCN-0.5, two weaker peaks at 120 and $170 \mathrm{ppm}$ appear, which are attributed to the $\mathrm{C}$ atom in the cyano group and the $\mathrm{C}$ atom adjacent to the cyano group, respectively [31]. Combined with the spectra of solid-state ${ }^{13} \mathrm{C}$ NMR, it can be explained that the cyano group existed in the terminal part of the structural unit of $\mathrm{g}-\mathrm{C}_{3} \mathrm{~N}_{4}$. The FTIR spectra of the sample provide direct evidence for the introduction of cyano groups. As shown in Fig. 3(b), MCN-0.5 and MCN exhibit obvious peaks at 812 and $1234-1644 \mathrm{~cm}^{-1}$, which can be attributed to the vibration of heptazine rings and stretching vibration modes of the aromatic $\mathrm{CN}$ heterocycles $[32,33]$. It is worth noting that MCN-0.5 shows an obvious absorption peak at $2173 \mathrm{~cm}^{-1}$, which is associated with the asymmetric vibration of the cyano group [34,35], indicating that the cyano group has been successfully introduced into MCN-0.5.

The XRD pattern reveals the influence of the formation of cyano groups on the crystal structure of the sample (Fig. 3(c)). Both MCN-0.5 and MCN show characteristic peaks of g- $\mathrm{C}_{3} \mathrm{~N}_{4}$ at $12.9^{\circ}$ and $27.6^{\circ}$ [36-38]. However, compared with that of MCN, the peak intensity of MCN-0.5 was significantly weaker, indicating that the grafted cyano groups destroyed the structural order within the framework of g- $\mathrm{C}_{3} \mathrm{~N}_{4}$. Fig. 3(d) shows the optical absorption properties of the sample. The absorption edge

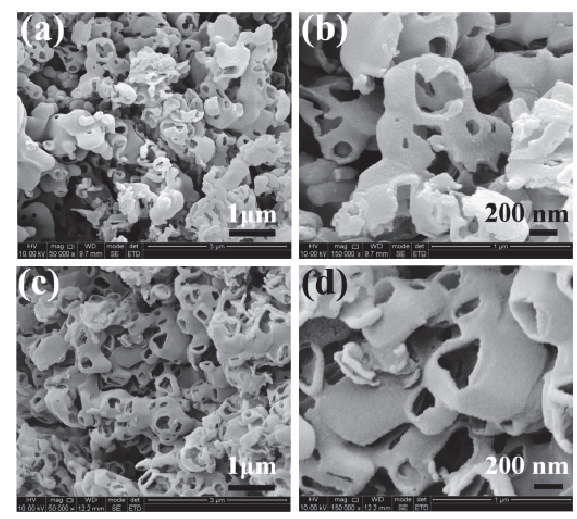

Fig. 2. (a,b) SEM images of MCN-0.5; (c,d) SEM images of MCN. The introduction of cyano groups did not affect the morphology of the porous nanosheets of the photocatalyst.
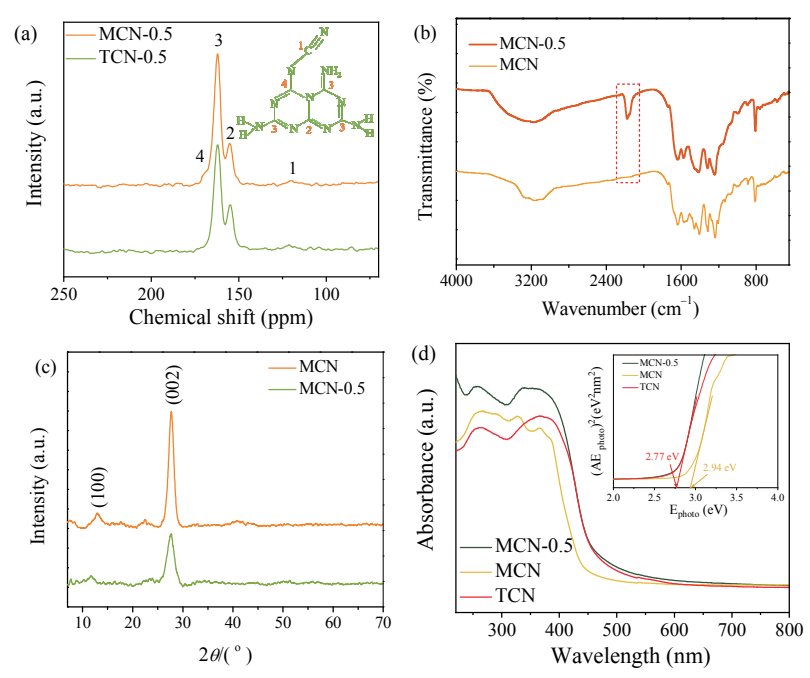

Fig. 3. (a) Solid-state ${ }^{13} \mathrm{C}$ NMR spectra of MCN-0.5 and TCN-0.5. (b) FTIR spectra of MCN-0.5 and MCN. (c) XRD patterns of MCN-0.5 and MCN. (d) UV-vis DRS spectra of MCN-0.5, MCN, and TCN (inset exhibits the plots of the calculated band gaps).

of MCN-0.5 appears red-shifted and the bandgap of MCN-0.5 becomes narrower compared with that of MCN. This result implies that the introduced cyano groups enhance the light absorption capacity of the photocatalyst, which is beneficial for the improvement of the photocatalytic activity. XPS measurements were used to reveal the effect of cyano group modification on the chemical environment of the photocatalyst (Fig. 4). Three peaks, at $398.6\left(\mathrm{~N}-(\mathrm{C})_{2}\right), 400.3\left(\mathrm{~N}-(\mathrm{C})_{3}\right)$, and $405.7 \mathrm{eV}$ $\left(\mathrm{n}-\pi^{*}\right)$ can be observed in the N $1 s$ spectra of MCN [39] (Fig. $4(\mathrm{c})$ ). The peak of MCN-0.5 at $\left(\mathrm{N}-(\mathrm{C})_{2}\right)$ is $0.3 \mathrm{eV}$ higher than that detected by MCN, which may be attributed to the electron-withdrawing effect of the cyano group that reduces the electron cloud density. Fig. 4(d) shows the valence band spectra of the sample. Compared with that of MCN, the valence band of MCN- 0.5 shows a positive shift, which is consistent with a previous report [40].

To prove that the cyano group can enhance the photocata-
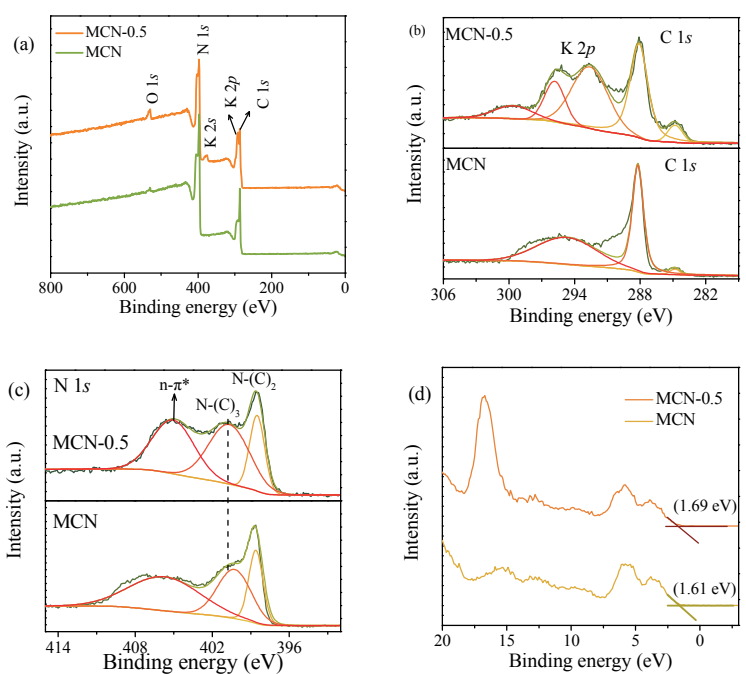

Fig. 4. XPS survey spectra (a), C $1 s$ and K $2 p$ (b), N $1 s$ (c) XPS spectra, and XPS valence band spectra (d) of MCN-0.5 and MCN. 
lytic activity of the photocatalyst, $\mathrm{CO}_{2}$ photoreduction experiments were conducted without sacrificial agents. Within $4 \mathrm{~h}$ of light irradiation, the main products of $\mathrm{CO}_{2}$ reduction were $\mathrm{CO}$ and $\mathrm{CH}_{4}$. In addition, the yield increased with time (Figs. 5(a) and (b)). MCN-0.5 exhibited the best photocatalytic activity (Fig. 5(c)). MCN-0.5 had a rate of $13.7 \mu \mathrm{mol} \cdot \mathrm{h}^{-1} \cdot \mathrm{g}^{-1}$ for CO evolution and $0.6 \mu \mathrm{mol} \cdot \mathrm{h}^{-1} \cdot \mathrm{g}^{-1}$ for $\mathrm{CH}_{4}$ evolution, far exceeding those of TCN (CO $5.4 \mu \mathrm{mol} \cdot \mathrm{h}^{-1} \cdot \mathrm{g}^{-1}$ and $\mathrm{CH}_{4} 0.3 \mu \mathrm{mol} \cdot \mathrm{h}^{-1} \cdot \mathrm{g}^{-1}$ ). The photocatalytic activity of MCN-0.5 is seen to be significantly higher than that of MCN, which indicates that the enhancement of photocatalytic activity is attributed to the contribution of active sites (cyano groups) rather than the porous structure.

To further prove that the enhanced photocatalytic activity of MCN-0.5 was attributable to the contribution of the active sites of the cyano group, MCN-0.5 was treated with $\mathrm{HCl}$ to remove the cyano group (MCN-0.5-HCl). Fig. 6(a) shows the FTIR spectra of the sample. Notably, the peak intensity of $\mathrm{MCN}-0.5-\mathrm{HCl}$ at $2170 \mathrm{~cm}^{-1}$ is significantly reduced, which is due to the reaction of hydrochloric acid and cyano groups to form urea groups [28]. Furthermore, a photocatalytic $\mathrm{CO}_{2}$ reduction experiment was performed, in which the yield of $\mathrm{CO}$ for MCN-0.5 was 5.22 times that of MCN-0.5-HCl (Fig. 6(b)). The removal of the cyano group significantly reduced the activity of MCN-0.5, indicating that the cyano group is the active site of the reaction. In order to eliminate the influence of the morphology on the activity, the TEM images of MCN-0.5 and MCN-0.5-HCl are shown in Fig. 6 (b) (inset). Both MCN-0.5 and $\mathrm{MCN}-0.5-\mathrm{HCl}$ showed a porous structure, indicating that the addition of $\mathrm{HCl}$ did not destroy the morphology of the photocatalyst. The photodeposition of Pt nanoparticles shows that the modification of cyano groups increases the active sites of the photocatalyst (Fig. S2). As shown in Figs. 6(c) and (d), a large number of well-dispersed Pt nanoparticles on MCN-0.5-Pt are reduced. However, only a few Pt nanoparticles were reduced on MCN-Pt and agglomerated on the edges and inside of the nanosheet (Figs. 6(e) and (f)). It can be inferred that MCN-0.5-Pt possesses many active sites due to the modification of the cyano group. Pt ions are anchored at the active sites and reduced to a large number of $\mathrm{Pt}$
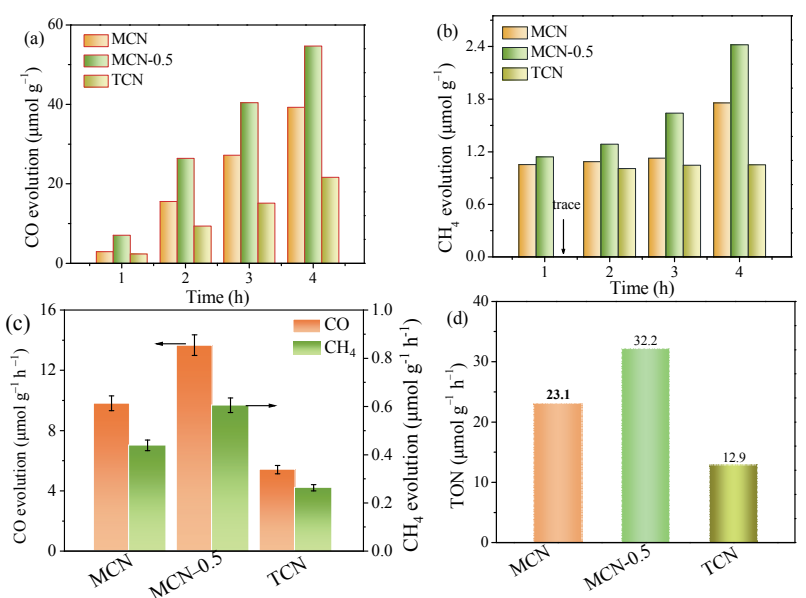

Fig. 5. The yields of $\mathrm{CO}$ (a) and $\mathrm{CH}_{4}$ (b) reduced by $\mathrm{CO}_{2}, \mathrm{CO}$ and $\mathrm{CH}_{4}$ evolution rate (c), and turnover numbers (TONs) of $\mathrm{CO}(\mathrm{d})$ generation over MCN-0.5, MCN, and TCN.
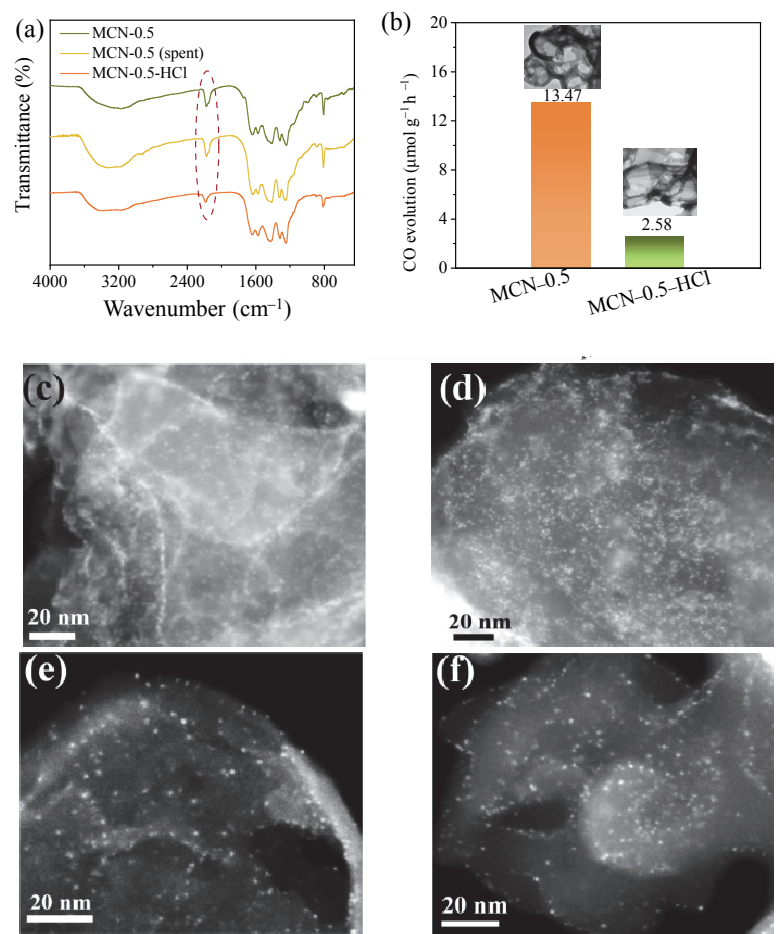

Fig. 6. (a) FTIR spectra of MCN-0.5, MCN-0.5 (spent), and $\mathrm{MCN}-0.5-\mathrm{HCl}$; (b) $\mathrm{CO}$ evolution rate over $\mathrm{MCN}-0.5$ and $\mathrm{MCN}-0.5-\mathrm{HCl}$ and corresponding SEM images (inset) of MCN-0.5 and MCN-0.5-HCl; (c,d) TEM images of MCN-0.5 loaded with Pt nanoparticles (MCN-0.5-Pt); (e,f) TEM images of MCN deposited with Pt nanoparticles (MCN-Pt). MCN-0.5-Pt and MCN-Pt were prepared by the photo-reduction method.

nanoparticles $[41,42]$. However, due to insufficiency of active sites in MCN-Pt, Pt ions tend to accumulate; therefore, only a small number of Pt nanoparticles are reduced.

$\mathrm{CO}_{2}$ adsorption experiments at 273 and $298 \mathrm{~K}$ were conducted to explore the underlying reasons for the enhancement of photocatalytic activity by cyano group modification (Figs. 7(a) and (b)). Surprisingly, MCN exhibited a stronger adsorp-
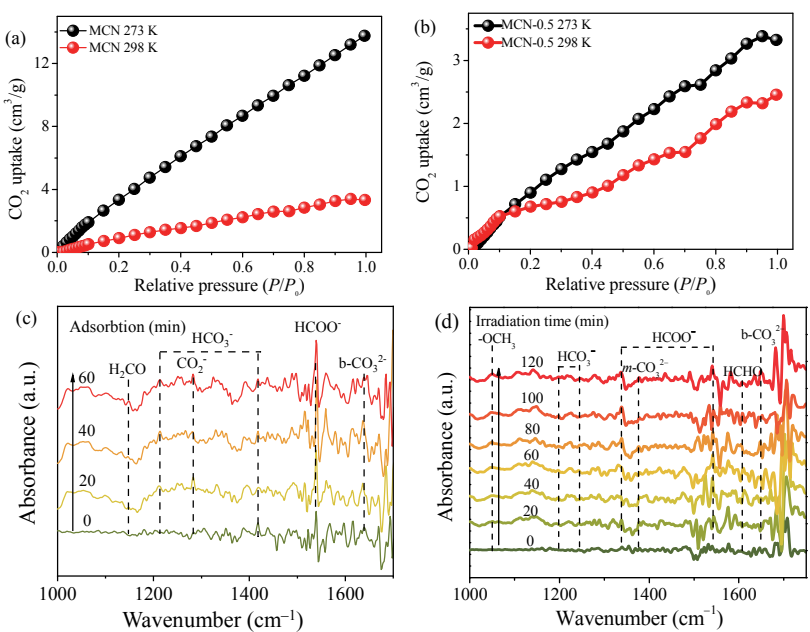

Fig. 7. $\mathrm{CO}_{2}$ adsorption isotherms of MCN (a) and MCN-0.5 (b) at $273 \mathrm{~K}$ and 298 K; In situ DRIFT spectra of MCN-0.5 under dark environment (c and light irradiation (d). 
tion capacity for $\mathrm{CO}_{2}$ than $\mathrm{MCN}-0.5$ at $273 \mathrm{~K}$. The characterization of $\mathrm{CO}_{2}$ adsorption performance indirectly shows that the enhanced activity for cyano group modification is attributable to the electron-withdrawing property of the cyano group, which promotes the separation of local carriers.

In situ DRIFT measurements were used to detect intermediate products that occur during the $\mathrm{CO}_{2}$ reduction process. In the process of $\mathrm{CO}_{2}$ adsorption by the photocatalyst, $\mathrm{CO}_{2}{ }^{-}, \mathrm{HCO}_{3}{ }^{-}$, and other species are detected (Fig. 7(c)). When the sample was exposed to light radiation, many intermediate products appeared (Fig. 7(d)), including $-\mathrm{OCH}_{3}\left(1048 \mathrm{~cm}^{-1}\right), \mathrm{HCO}_{3}{ }^{-}$ (1198 and $1244 \mathrm{~cm}^{-1}$ ), $\mathrm{HCOO}^{-}\left(1337\right.$ and $\left.1541 \mathrm{~cm}^{-1}\right), \mathrm{m}-\mathrm{CO}_{3}{ }^{2-}$ (1375 $\left.\mathrm{cm}^{-1}\right)$, HCHO (1607 $\left.\mathrm{cm}^{-1}\right)$, and b- $\mathrm{CO}_{3}{ }^{2-}\left(1648 \mathrm{~cm}^{-1}\right)$ [43-45]. Among them, the peak intensity of $\mathrm{HCOO}^{-}$first increased and then decreased, indicating that $\mathrm{COOH}^{*}$ generated $\mathrm{CO}$ [46]. According to reports, ${ }^{*} \mathrm{CH}_{3} \mathrm{O}$ is a key product for the formation of $\mathrm{CH}_{4}$, and the peak intensity of $-\mathrm{OCH}_{3}$ increases with time, which is conducive to the formation of $\mathrm{CH}_{4}$.

DFT calculations were used to study the influence of cyano groups on the electronic band structure of MCN-0.5. The optimized structure model of MCN-0.5 (Fig. 8(b)) shows that the grafting of cyano groups to the g- $\mathrm{C}_{3} \mathrm{~N}_{4}$ framework causes obvious structural deformation. The calculated band structures of MCN and MCN-0.5 (Figs. S3(a) and (b)) show that the introduction of cyano groups reduces the band gap value of MCN from 2.46 to $2.37 \mathrm{eV}$, which is in good agreement with the results of DRS. The partial density of states (PDOS) analysis of MCN (Fig. 8(c)) shows that the valence band of MCN is mainly composed of $\mathrm{N} 2 p$ orbitals, and the conduction band mainly contains $\mathrm{C} 2 p$ and $\mathrm{N} 2 p$ orbitals. Compared with those of MCN, the peaks of the N $2 p$ orbitals on the left side of the Fermi level in the PDOS plot of MCN-0.5 (Fig. 8(d)) become sharper and discontinuous. This may be because the introduction of cyano groups destroys the order of structural units. The results of DFT calculations show that the introduction of cyano groups has a significant impact on the electronic band structure, and changes in the electronic band structure may directly affect the photocatalytic activity.

The TRPL spectra (Fig. 9(a)) reveal the lifetime of photogenerated carriers for the prepared photocatalyst. Compared with that of TCN, the lifetime of carriers in MCN-0.5 is significantly reduced. The reduction in lifetime means that carriers (a)

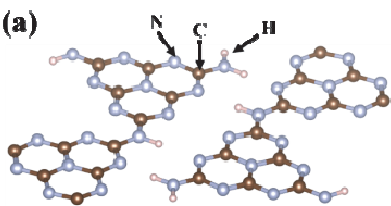

(b)

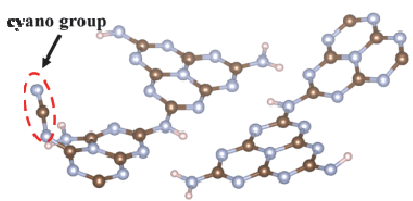

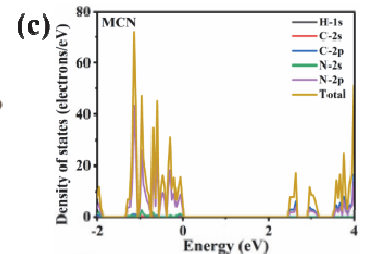

(d)

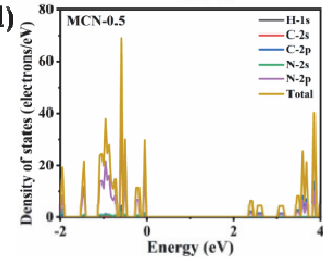

Fig. 8. The optimized structure models of MCN (a) and MCN-0.5 (b); Calculated DOS for MCN (c) and MCN-0.5 (d).
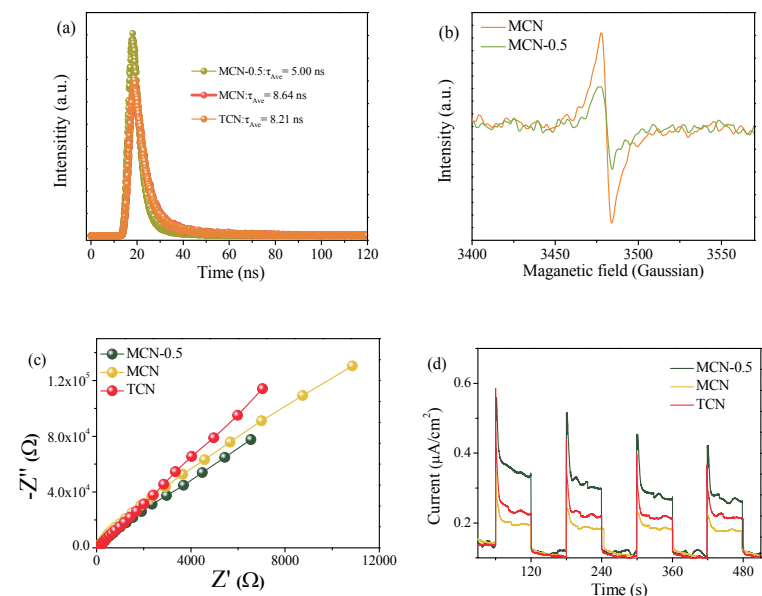

Fig. 9. (a) TRPL spectra of MCN-0.5, MCN, and TCN; (b) EPR spectra of MCN-0.5 and MCN; EIS Nyquist curves (c), and transient photocurrent response plots (d) of MCN-0.5, MCN, and TCN.

are more easily transferred through non-radiative pathways to promote carrier separation [47]. Fig. 9(b) shows the EPR spectra of MCN-0.5 and MCN. A single peak of the two samples was detected with a g value of 2.004 [48], which is attributed to the unpaired electrons on the aromatic ring carbon [49]. Notably, the peak intensity of MCN-0.5 is lower than that of MCN, which indicates that the introduced cyano group reduces the number of lone pairs of electrons. The photoelectrochemical characterization further showed that the cyano group promoted the carrier separation of MCN-0.5. The EIS Nyquist plots of MCN, MCN-0.5, and TCN are shown in Fig. 9(c). Compared with TCN, MCN-0.5 exhibits a smaller arc radius, which means improved carrier migration in MCN-0.5 [50-54]. Furthermore, MCN-0.5 exhibits the highest photocurrent density among the prepared samples (Fig. 9(d)), which means that carriers are more effectively separated at the working electrode. The enhanced separation of carriers indicates that the cyano groups as electron-withdrawing groups greatly reduce carrier recombination.

In combination with the above discussion, the mechanism of MCN-0.5 for photocatalytic $\mathrm{CO}_{2}$ reduction is shown in Fig. 10. The valence band of $\mathrm{g}-\mathrm{C}_{3} \mathrm{~N}_{4}$ is mainly composed of $\mathrm{N} 2 p$ orbitals of $\mathrm{N}$ atoms [55-57]. Under visible light irradiation, electrons on the $\mathrm{N}$ atoms get excited. Therefore, the $\mathrm{N}$ atoms act as electron

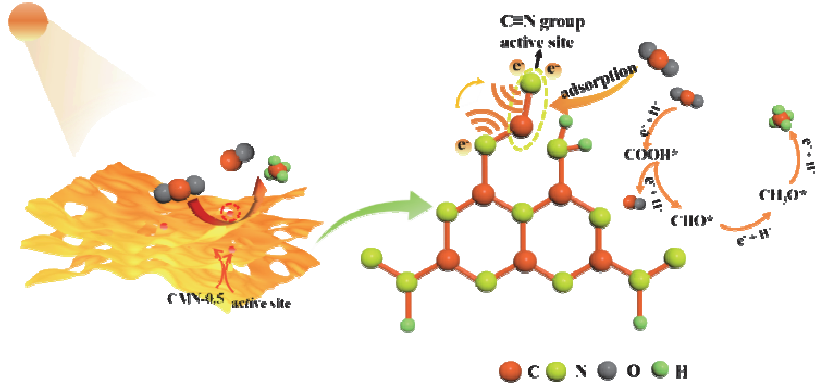

Fig. 10. Proposed mechanism of MCN-0.5 for photocatalytic $\mathrm{CO}_{2}$ conversion. The cyano group was grafted onto the MCN-0.5 as an electron acceptor. Besides, the cyano group possesses good electron-withdrawing properties, improving carrier separation, and acting as an active site to participate in the photocatalytic $\mathrm{CO}_{2}$ reduction reaction. 

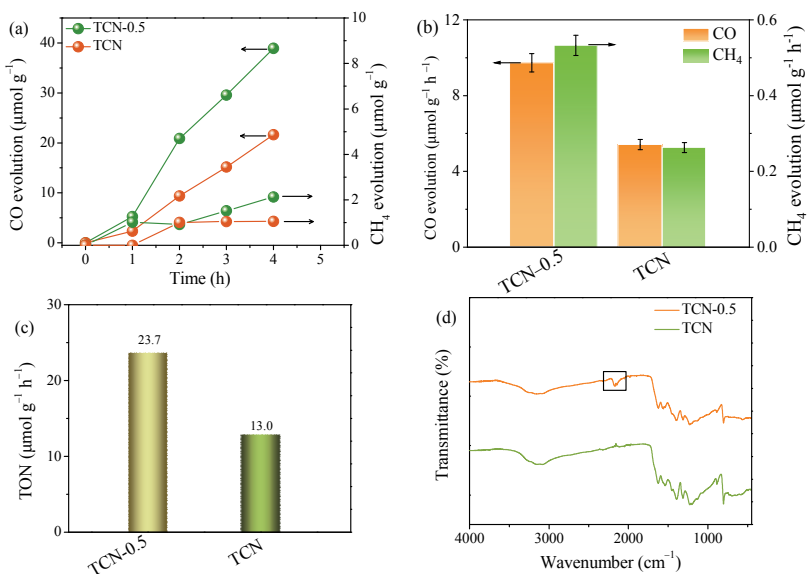

Fig. 11. The yields of $\mathrm{CO}$ and $\mathrm{CH}_{4}$ (a), evolution rate of $\mathrm{CO}$ and $\mathrm{CH}_{4}$ (b), TONs for CO generation (c), and FTIR spectra (d) over TCN-0.5 and TCN.

donors. The cyano group possesses good electron-extracting ability and is often used as an electron acceptor [58]. Therefore, when the cyano group is grafted onto the g- $\mathrm{C}_{3} \mathrm{~N}_{4}$ framework, a local intramolecular donor-acceptor (D-A) system will be formed between the cyano group and the adjacent $\mathrm{N}$ atom. The D-A system promotes the effective transfer of intramolecular charges and reduces carrier recombination [59,60]. The grafting of cyano groups redistributes local charges and makes electrons gather near the cyano groups. Therefore, the cyano groups uniformly anchored on MCN-0.5 acted as active sites to participate in the photocatalytic reaction. The porous structure further increases the exposure of the active sites and increases the chance of contact between the active sites and the reactant.

In order to verify the general applicability of the cyano group to enhance the photocatalytic activity of g- $\mathrm{C}_{3} \mathrm{~N}_{4}$, the sample was prepared with melamine as the precursor of g- $\mathrm{C}_{3} \mathrm{~N}_{4}$ and then grafted with the cyano group (TCN-0.5). The introduction of cyano groups into TCN- 0.5 was confirmed by the FTIR spectra (Fig. 11(d)). As shown in Fig. 11(a), within $4 \mathrm{~h}$ of irradiation, the yield of $\mathrm{CO}$ for TCN-0.5 was significantly higher than that for TCN, and the evolution rates of $\mathrm{CO}$ and $\mathrm{CH}_{4}$ for TCN-0.5 were 9.7 and $0.5 \mu \mathrm{mol} \cdot \mathrm{h}^{-1} \cdot \mathrm{g}^{-1}$, respectively (Fig. 11(b)), considerably exceeding those for TCN (CO $5.4 \mu \mathrm{mol} \cdot \mathrm{h}^{-1} \cdot \mathrm{g}^{-1}$ and $\mathrm{CH}_{4}$ $0.3 \mu \mathrm{mol} \cdot \mathrm{h}^{-1} \cdot \mathrm{g}^{-1}$ ), indicating the versatility of the strategy for introducing cyano groups to enhance the photocatalytic activity of g- $\mathrm{C}_{3} \mathrm{~N}_{4}$.

\section{Conclusions}

In summary, cyano-modified porous g- $\mathrm{C}_{3} \mathrm{~N}_{4}$ nanosheets (MCN-0.5) were synthesized through molecular self-assembly and alkali-assisted strategies. The cyano group acted as the active site of the photocatalytic reaction, because the good electron-extracting property of the cyano group promoted carrier separation. Benefiting from the effect of the active sites, MCN-0.5 exhibited significantly enhanced activity for $\mathrm{CO}_{2}$ reduction under visible light irradiation. Notably, the photocatalytic activity of the photocatalyst was significantly reduced when the cyano groups were removed by $\mathrm{HCl}$ treatment, fur- ther verifying the role of cyano groups as active sites. The photoreduction of Pt nanoparticles intuitively indicated that the introduction of cyano groups provided more active sites for the reaction. Furthermore, controlled experiments showed that g- $\mathrm{C}_{3} \mathrm{~N}_{4}$ grafted with cyano groups using melamine as the precursor exhibited enhanced photocatalytic activity, which proved the versatility of the strategy for enhancing the activity of g- $\mathrm{C}_{3} \mathrm{~N}_{4}$ via cyano group modification. The mechanism of enhanced photocatalytic activity for $\mathrm{CO}_{2}$ reduction by cyano-modified g- $\mathrm{C}_{3} \mathrm{~N}_{4}$ was investigated using in situ diffuse reflectance infrared Fourier transform spectroscopy and theoretical calculations. This work provides a promising route for promoting efficient solar energy conversion by designing active sites in the photocatalyst.

\section{Electronic supporting information}

Supporting information is available in the online version of this article.

\section{References}

[1] Q. Y. Chen, S. J. Li, H. Y. Xu, G. F. Wang, Y. Qu, P. F. Zhu, D. S. Wang, Chin. J. Catal., 2020, 41, 514-523.

[2] F. Xu, K. Meng, B. Cheng, S. Wang, J. Xu, J. Yu, Nat. Commun., 2020, $11,4613$.

[3] J. Albero, Y. Peng, H. Garcia, ACS Catal., 2020, 10, 5734-5749.

[4] Y. Xia, B. Cheng, J.J. Fan, J.G. Yu, G. Liu, Sci. China Mater., 2020, 63, 552-565.

[5] Y. Xia, Z. H. Tian, T. Heil, A.Y. Meng, B. Cheng, S.W. Cao, J. G. Yu, M. Antonietti, Joule, 2019, 3, 2792-2805.

[6] Y. Xia, J. G. Yu, Chem, 2020, 6, 1039-1040.

[7] J. Khamrai, I. Ghosh, A. Savateev, M. Antonietti, B. Koenig, ACS Catal., 2020, 10, 3526-3532.

[8] M. Wang, J. Cheng, X. Wang, X. Hong, J. Fan, H. Yu, Chin. J. Catal, 2021, 42, 37-45.

[9] J. Luo, Z. Lin, Y. Zhao, S. Jiang, S. Song, Chin. J. Catal., 2020, 41, 122-130.

[10] X. B. Li, J. Xiong, Y. Xu, Z. J. Feng, J. T. Huang, Chin. J. Catal, 2019, $40,424-433$.

[11] X. N. Wang, L. Wu, Z. W. Wang, H. Y. Wu, X. M. Zhou, H. Y. Ma, H. Z. Zhong, Z. Xing, G. X. Cai, C. Z. Jiang, F. Ren, Sol. RRL, 2019, 3,1800298 .

[12] Y. Li, M. Zhang, L. Zhou, S. Yang, Z. Wu, Y. Ma, Acta Phys.-Chim. Sin. 2021, 37, 2009030.

[13] Y. Li, D. Zhang, J. Fan, Q. Xiang, Chin. J. Catal., 2021, 42, 627-636.

[14] Y. F. Li, M. H. Zhou, B. Cheng, Y. Shao, J. Mater. Sci. Technol., 2020, $56,1-17$.

[15] A. Y. Meng, Z. Y. Teng, Q. T. Zhang, C. L. Su, Chem. Asian J., 2020, 15, 3405-3415.

[16] Q. Q. Liu, J. Y. Shen, X. H. Yu, X. F. Yang, W. Liu, J. Yang, H. Tang, H. Xu, H. M. Li, Y. Y. Li, J. S. Xu, Appl. Catal. B, 2019, 248, 84-94.

[17] K. Sun, J. Shen, Q. Liu, H. Tang, M. Zhang, S. Zulfiqar, C. Lei, Chin. J. Catal., 2020, 41, 72-81.

[18] Q. Xiang, F. Li, D. Zhang, Y. Liao, H. Zhou, Appl. Surf. Sci., 2019, 495, 143520.

[19] X. Li, J. Zhang, F. Zhou, H. Zhang, J. Bai, Y. Wang, H. Wang, Chin. J. Catal., 2018, 39, 1090-1098.

[20] S. Yu, J. Li, Y. Zhang, M. Li, F. Dong, T. Zhang, H. Huang, Nano Energy, 2018, 50, 383-392. 


\section{Graphical Abstract}

Chin. J. Catal., 2021, 42: 1608-1616 doi: 10.1016/S1872-2067(20)63776-7

\section{Construction of efficient active sites through cyano-modified graphitic carbon nitride for photocatalytic $\mathrm{CO}_{2}$ reduction}

Fang Li, Xiaoyang Yue, Haiping Zhou, Jiajie Fan, Quanjun Xiang*

University of Electronic Science and Technology of China; Zhengzhou University

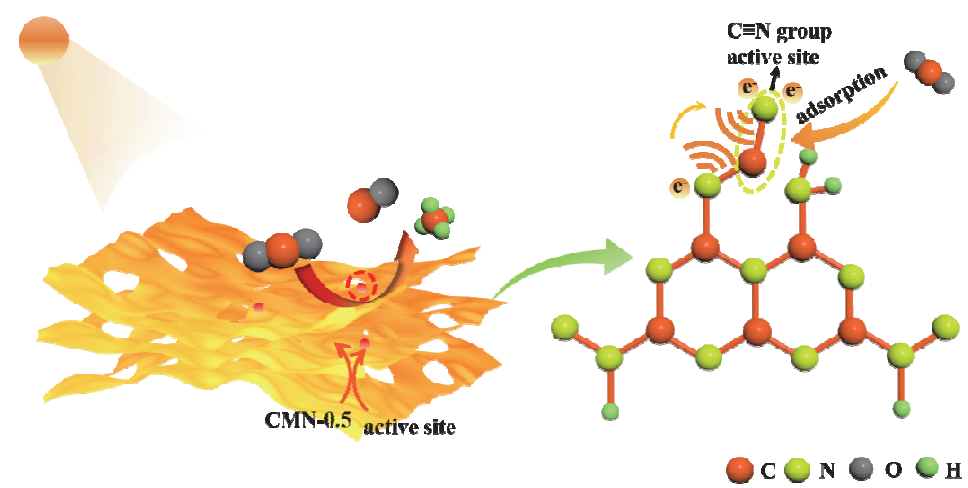

Cyano-modified porous g- $\mathrm{C}_{3} \mathrm{~N}_{4}$ nanosheets (MCN-0.5) with cyano groups as active sites exhibited enhanced photocatalytic activity for $\mathrm{CO}_{2}$ reduction.

[21] Y. Li, X. Li, H. Zhang, J. Fan, Q. Xiang, J. Mater. Sci. Technol, 2020, $56,69-88$.

[22] G. Liu, G. Zhao, W. Zhou, Y. Liu, H. Pang, H. Zhang, D. Hao, X. Meng, P. Li, T. Kako, J. Ye, Adv. Funct. Mater., 2016, 26, 6822-6829.

[23] V. W. H. Lau, I. Moudrakovski, T. Botari, S. Weinberger, M. B. Mesch, V. Duppel, J. Senker, V. Blum, B. V. Lotsch, Nat. Commun., 2016, 7, 12165.

[24] D. Zhang, X. Han, T. Dong, X. Guo, C. Song, Z. Zhao, J. Catal., 2018, $366,237-244$.

[25] F. Li, D. Zhang, Q. Xiang, Chem. Commun., 2020, 56, 2443-2446.

[26] Y. Li, X. Li, H.W. Zhang, Q. J. Xiang, Nanoscale Horiz., 2020, 5, 765-786.

[27] M. Shalom, S. Inal, C. Fettkenhauer, D. Neher, M. Antonietti, J. Am. Chem. Soc., 2013, 135, 7118-7121.

[28] V. W. H. Lau, V. W. Z. Yu, F. Ehrat, T. Botari, I. Moudrakovski, T. Simon, V. Duppel, E. Medina, J. K. Stolarczyk, J. Feldmann, V. Blum, B. V. Lotsch, Adv. Energy Mater., 2017, 7, 1602251.

[29] X. Ma, Q. Xiang, Y. Liao, T. Wen, H. Zhang, Appl. Surf. Sci., 2018, 457, 846-855.

[30] Y. Xiao, G. Tian, W. Li, Y. Xie, B. Jiang, C. Tian, D. Zhao, H. Fu, J. Am. Chem. Soc., 2019, 141, 2508-2515.

[31] H. Yu, R. Shi, Y. Zhao, T. Bian, Y. Zhao, C. Zhou, G. I. N. Waterhouse, L. Z. Wu, C. H. Tung, T. Zhang, Adv. Mater., 2017, 29, 1605148.

[32] P. F. Xia, M. Antonietti, B. C. Zhu, T. Heil, J. G. Yu, S. W. Cao, Adv. Funct. Mater, 2019, 29, 1900093.

[33] Y. Li, D. Zhang, X. Feng, Q. Xiang, Chin. J. Catal., 2020, 41, 21-30.

[34] Y. Cui, Z. Ding, X. Fu, X. Wang, Angew. Chem., Int. Ed., 2012, 51, 11814-11818.

[35] H. Yu, H. Ma, X. Wu, X. Wang, J. Fan, J. Yu, Sol. RRL, 2020, https://doi.org/10.1002/solr.202000372.

[36] Y. S. Jun, E. Z. Lee, X. Wang, W. H. Hong, G. D. Stucky, A. Thomas, Adv. Funct. Mater., 2013, 23, 3661-3667.

[37] M. Wang, J. Cheng, X. Wang, X. Hong, J. Fan, H. Yu, Chin. J. Catal., 2021, 42, 37-45.
[38] H. Yu, J. Xu, D. Gao, J. Fan, J. Yu, Sci. China Mater., 2020, 63, 2215-2227.

[39] V. V. Shvalagin, G. V. Korzhak, S. Y. Kuchmiy, M. A. Skoryk, O. V. Selyshchev, D. R. T. Zahn, J. Photochem. Photobiol. A, 2020, 390, 112295.

[40] H. Tan, X. Gu, P. Kong, Z. Lian, B. Li, Z. Zheng, Appl. Catal. B, 2019, $242,67-75$.

[41] Z. Jiang, M. A. Isaacs, Z. W. Huang, W. Shangguan, Y. Deng, A. F. Lee, ChemCatChem, 2017, 9, 4268-4274.

[42] Y. Matsumoto, S. Ida, T. Inoue, J. Phys. Chem. C, 2008, 112, 11614-11616.

[43] L. Cheng, H. Yin, C. Cai, J. Fan, Q. Xiang, Small, 2020, 16, 2002411.

[44] Y. Yang, F. Li, J. Chen, J. Fan, Q. Xiang, ChemSusChem, 2020, 13, 1979-1985.

[45] L. Cheng, D. Zhang, Y. Liao, J. Fan, Q. Xiang, Chin. J. Catal., 2021, 42, 131-140.

[46] Z. Jiang, H. Sun, T. Wang, B. Wang, W. Wei, H. Li, S. Yuan, T. An, H. Zhao, J. Yu, P. K. Wong, Energy Environ. Sci., 2018, 11, 2382-2389.

[47] J. W. Zhang, S. Gong, N. Mahmood, L. Pan, X. W. Zhang, J. J. Zou, Appl. Catal. B, 2018, 221, 9-16.

[48] H. Che, C. Liu, G. Che, G. Liao, H. Dong, C. Li, N. Song, C. Li, Nano Energy, 2020, 67, 104273.

[49] S. Li, Y. Peng, C. Hu, Z. Chen, Appl. Catal. B, 2020, 279, 119401.

[50] F. He, A. Y. Meng, B. Cheng, W. K. Ho, J. G. Yu, Chin. J. Catal., 2020, $41,9-20$.

[51] D. D. Ren, R.C. Shen, Z.M. Jiang, X.Y. Lu, X. Li, Chin. J. Catal., 2020, $41,31-40$.

[52] R. C. Shen, J. Xie, Q. J. Xiang, X. B. Chen, J. Z. Jiang, X. Li, Chin. J. Catal., 2019, 40, 240-288.

[53] R. Shen, Y. Ding, S. Li, P. Zhang, Q. Xiang, Y. H. Ng, X. Li, Chin. J. Catal., 2021, 42, 25-36.

[54] X. Li, X. Wu, S. Liu, Y. Li, J. Fan, K. Lv, Chin. J. Catal., 2020, 41, 1451-1467. 
[55] Q. He, F. Zhou, S. Zhan, Y. Yang, Y. Liu, Y. Tian, N. Huang, Appl. Surf. Sci., 2017, 391, 423-431.

[56] G. Dong, K. Zhao, L. Zhang, Chem. Commun., 2012, 48, 6178-6180.

[57] B. Zhu, B. Cheng, L. Zhang, J. Yu, Carbon Energy, 2019, 1, 32-56.

[58] C. Yao, Y. Yang, L. Li, M. Bo, J. Zhang, C. Peng, Z. Huang, J. Wang, J.
Phys. Chem. C, 2020, 124, 23059-23068.

[59] X. Fan, L. Zhang, R. Cheng, M. Wang, M. Li, Y. Zhou, J. Shi, ACS Catal, 2015, 5, 5008-5015.

[60] H. Ou, X. Chen, L. Lin, Y. Fang, X. Wang, Angew. Chem. Int. Ed., 2018, $57,8729-8733$.

\title{
氰基修饰石墨相氮化碳构建高效的活性位点用于光催化还原 $\mathrm{CO}_{2}$
}

\author{
李 访 ${ }^{\mathrm{a}, \mathrm{b}}$, 岳晓阳 ${ }^{\mathrm{a}}$, 周海平 ${ }^{\mathrm{c}}$, 范佳杰 ${ }^{\mathrm{d}}$, 向全军 ${ }^{\mathrm{a}, \mathrm{b},{ }^{*}}$ \\ ${ }^{\mathrm{a}}$ 电子科技大学电子科学与工程学院, 电子薄膜与集成器件国家重点实验室, 四川成都610054

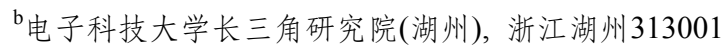 \\ ${ }^{\mathrm{c}}$ 电子科技大学材料与能源学院, 四川成都610054 \\ d郑州大学材料科学与工程学院, 河南郑州 450002
}

\begin{abstract}
摘要: 作为影响光催化反应的关键因素, 光催化剂的活性位点数量直接决定了光催化活性. 传统石墨相氮化碳 $\left(\mathrm{g}-\mathrm{C}_{3} \mathrm{~N}_{4}\right)$ 由 于活性位点不足而表现出较弱的光催化活性. 为了增加 $\mathrm{g}-\mathrm{C}_{3} \mathrm{~N}_{4}$ 的活性位点数量, 研究人员采取了各种策略, 包括杂原子掺 杂、表面改性和空位工程. 其中, 表面改性是增加催化剂活性位点的有效策略之一. 氧基具有很强的吸电子能力, 可在光催 化反应中作为活性位点. 然而, 关于氧基作为 $\mathrm{CO}_{2}$ 光还原活性位点的研究并不多, 特别是对于氧基修饰增强 $\mathrm{g}-\mathrm{C}_{3} \mathrm{~N}_{4}$ 活性的 机理尚不清楚. 构建多孔结构是暴露催化剂活性位点的有效措施之一. 多孔结构可以有效改善纳米片的团聚, 促进活性位 点暴露, 增大反应物与活性位点间的接触机会; 并且相互连接的多孔网络可形成独特的传输通道, 进一步促进载流子迁移.

本文通过分子自组装和碱辅助策略合成了氧基改性的多孔g- $\mathrm{C}_{3} \mathrm{~N}_{4}$ 纳米片(MCN-0.5). 氧基由于具有良好的吸电子特 性, 促进了局部载流子分离, 并充当了光催化反应的活性位点. 受益于活性位点的影响, MCN-0.5表现出显著增强的光催化 $\mathrm{CO}_{2}$ 还原活性. 在不添加牺牲剂和助催化剂的条件下, $\mathrm{MCN}-0.5$ 样品上 $\mathrm{CO}$ 和 $\mathrm{CH}_{4}$ 产率达到 13.7 和 $0.6 \mu \mathrm{mol} \cdot \mathrm{h}^{-1} \cdot \mathrm{g}^{-1}$, 分别是传 统煅烧法制备的 $\mathrm{g}-\mathrm{C}_{3} \mathrm{~N}_{4}(\mathrm{TCN})$ 产生 $\mathrm{CO}$ 和 $\mathrm{CH}_{4}$ 产率的 2.5 和 2 倍. 通过盐酸处理MCN-0.5除去氰基, 并没有破坏样品的形貌结 构, 但催化剂的光催化活性显著降低,证实了氰基活性位点的作用. 光还原 $\mathrm{Pt}$ 纳米颗粒的实验结果表明, 与对照样品相比, 氧基修饰的样品上还原的 $\mathrm{Pt}$ 纳米颗粒更多, 进一步证实了引入氰基为光还原反应提供了更多活性位点. $\mathrm{CO}_{2}$ 等温吸附测试 结果表明, $\mathrm{MCN}-0.5$ 对 $\mathrm{CO}_{2}$ 的吸附能力不如对照样品, 间接证明氧基能成为活性位点是由于其良好的吸电子能力促进了局 部载流子分离. 瞬态荧光光谱、光电化学表征结果表明, 氰基修饰增强了载流子迁移和分离能力. 根据理论计算和原位红 外光谱提出了㲵基修饰增强 $\mathrm{g}-\mathrm{C}_{3} \mathrm{~N}_{4}$ 光催化还原 $\mathrm{CO}_{2}$ 活性的作用机理. 以三聚氧胺为前驱体接枝氰基的 $\mathrm{g}-\mathrm{C}_{3} \mathrm{~N}_{4}$ 也表现出比体 相 $\mathrm{g}-\mathrm{C}_{3} \mathrm{~N}_{4}$ 明显增强的光催化还原 $\mathrm{CO}_{2}$ 活性, 这证明了氰基改性增强 $\mathrm{g}-\mathrm{C}_{3} \mathrm{~N}_{4}$ 活性策略的通用性. 本文通过在光催化剂材料中 设计活性位点为太阳能高效转化提供了一个有效途径.
\end{abstract}

关键词: 石墨相氮化碳; 氧基修饰; 活性位点; 电子受体; 多孔结构; 光催化还原 $\mathrm{CO}_{2}$

收稿日期: 2021-01-12. 接受日期: 2021-02-01. 上网时间: 2021-05-05.

*通讯联系人. 电话/传真: (028)83207063; 电子信箱: xiangqj@uestc.edu.cn

基金来源：国家自然科学基金(51672099，52073263); 四川省科技计划资助(2019JDRC0027, 2019YFG0222); 中央高校基金 (2017-QR-25).

本文的电子版全文由Elsevier出版社在ScienceDirect上出版(http://www.sciencedirect.com/journal/chinese-journal-of-catalysis). 